\title{
Craniopharyngioma with infrasellar extension in an eight- year boy: An unusual entity
}

\author{
Guru Dutta Satyarthee* \\ Department of Neurosurgery, Neurosciences Centre, AIIMS, New Delhi, India
}

\begin{abstract}
Craniopharyngiomas are mostly lactated in the suprasellar region. However, ectopic craniopharyngioma may be rarely located in the infrasellar region. We report an 8-year - old boy, who had large craniopharyngioma predominantly involving sella turcica, sphenoid sinus, ethmoid sinus, and nasal cavity. He presented with progressive visual impairment. He underwent transsphenoidal decompression. He made unremarkable visual recovery following surgery.
\end{abstract}

\section{Introduction}

Craniopharyngioma accounts for about 3\% of all intracranial tumours [1]. Mott and Barrett, in 1899 postulated its origin from Rathke's pouch or hypophyseal duct [2]. The anterior wall of Rathke's pouch forms both the pars tuberalis and pars distalis of anterior lobe of pituitary, being regarded as the commonest site of origin of craniopharyngioma and rarely also occur along the carniopharyngeal duct which extends from the pharynx up to the floor of sella [2-4]. Craniopharyngioma is mostly located usually above the sella floor but extension into sinus is very rare and with unusual [5-17]. About eleven cases of infrasellar craniopharyngioma are reported in the literature, whose either majority of the chief epicenter or wholly tumour is located in the infrasellar region. Craniopharyngioma with such locations have termed with many confusing terminology including these are ectopic basisphenoidal [5-30] infrasellar [21,28,31-37] pharyngeal [16], nasopharyngeal $[17,29,34,38]$, purely pharyngeal [16], and purely nasopharyngeal located [38]. Our case is unusual in having extensive extension into nasal cavity, nasopharynx, and ethmoid sinus with intracranial component lying above sella causing indenting floor of third ventricle.

\section{Case illustration}

An-8 year old boy presented with progressive headache and diminution of visual acuity along with difficulty in reading the blackboard. He had no features of endocrinopathy. He was of average built and medium height. The visual acuity in the right eye was $6 / 12$ and $6 / 36$ in the left eye. Fundi revealed pale optic discs. He had bitemporal field defect on bedside confrontation test, however, the rest of the neurological examinations were within normal limit. Routine laboratory investigation and endocrinological profiles were within normal limit. Plain $\mathrm{x}$-ray skull demonstrated destruction of sella turcica with opacification sphenoid sinus. A cranial computed tomography scan revealed hypodense lesion extending into ethmoid sinus with hyper-dense component in infrasellar and sellar region. Magnetic resonance imaging brain, T1 weighted, saggital section image showed heterogeneous high signal intensity mass lesion extending into the sphenoid sinus, nasal cavity and extending into sellar and suprasellar region (Figure 1) which on T2WI, axial section showed areas of hyperintensity in the ethmoid and sphenoid sinus representing cystic component of craniopharyngioma (Figure 2). On contrast administration, solid component only showed enhancement. Based on clinical feature and neuro-imaging a probable diagnosis of craniopharyngioma was made and lesions including mucocele were also kept as differential diagnosis. He was operated through sublabial rhinoseptal transsphenoidal decompression. A machine oil like dark fluid was drained. Subtotal removal of sellar solid component could be achieved as chalky calcified component was attached to cavernous sinus and part was left behind in view of preoperative intact neurological

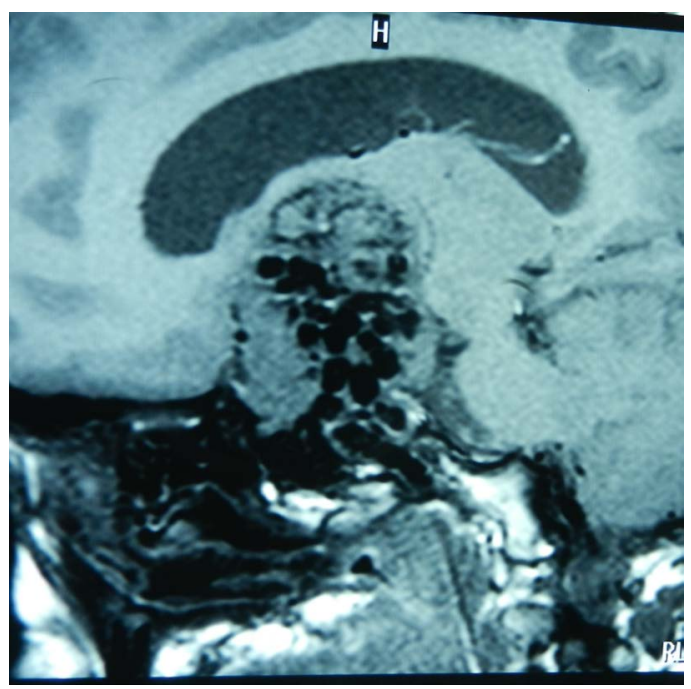

Figure 1. MRI brain, T1WI sagittal section, showing heterogeneous mass lesionextendinginto sphenoid sinus and nasal cavity, ethmoid and sphenoid sinus with sellar and suprasellar component.

Correspondence to: Dr. Guru Dutta Satyarthee, Associate Professor, Department of Neurosurgery, Room No. 714, Neurosciences Centre, AIIMS, New Delhi, India, E-mail: duttaguru2002@yahoo.com

Key words: craniopharyngioma, infrasellar extension, management

Received: June 13, 2017; Accepted: June 27, 2017; Published: June 30, 2017 


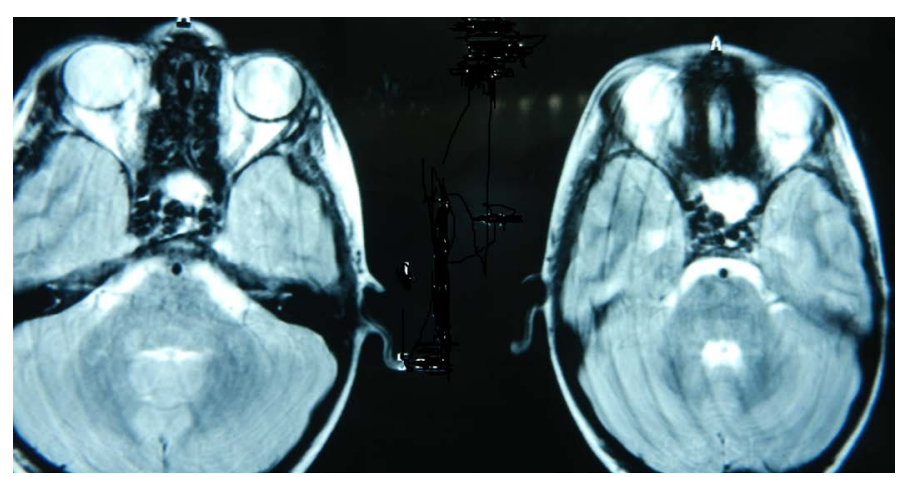

Figure 2. MRI brain of 8-year -boy, T2WI axial section showing hyperintenselesion extending into ethmoid and sphenoid sinus,representing cystic component of craniopharyngioma, making suitable for transsphenoidal approach.

status. Histopathological examination of resected specimen was compatible with squamus variety of craniopharyngioma. He made unremarkable recovery in visual acuity and field of vision in the postoperative period. He was discharged from hospital on the seventh postoperative period. A follow-up CT scan revealed residual in sell and sphenoid sinus, In the follow-up, he was referred for radiotherapy. $\mathrm{He}$ received 54 Gy of radiation therapy. An MRI done at 2 year following surgery revealed residual mass but no tumor growth. At the last followup at three years following surgery, he was doing well.

\section{Discussion}

Craniopharyngioma commonly arises from remnant of Rathke's pouch extending from pharynx to sella. Mostly craniopharyngioma are located in the sellar and suprasellar region. Although ectopic craniopharyngioma may be located in infrasellar region, involving sphenoid sinus and nasopharynx. It may also be located ectopically in the third ventricle, which causes obstructive hydrocephalus. These tumours usually present during $2^{\text {nd }}$ and third decades of life [32]. Infrasellar craniopharyngioma may occupy different anatomical locations i.e. may be completely localized in compartment of paranasal sinuses i e. ethmoid sinus [33], or may be entirely located in nasopharynx $[7,35]$. These subset of ectopic craniopharyngioma may present with symptoms like nasal obstruction or chronic sinusitis. However, vast majority of reported infrasellar craniopharyngioma crosses the anatomical boundary and extends into adjoining nasopharynx, paranasal sinus or sella turcica responsible or varied presentation. Rarely sella turcica may be completely spared and grow extensively into the sphenoid sinus, nasopharynx, nasal cavity or ethmoid sinus $[4,6,7,9,17,22-24,29,31,39,40]$.

Such craniopharyngioma may have completely different presentation from typical endocrinopathy and visual deficit and instead it may present with conglomeration of variable symptoms, which depends on extent of involvement and obstruction of ostia of the paranasal sinuses causing difficulty in breathing, nasal obstruction and sinus headache. These craniopharyngioma with sellar component can also encroach and the sella floor and cause direct compression of pituitary gland or secondary to vascular compromise leads endocrinopathy [10-17,19,21,25,27,28,32]. So, majority of infrasellar reported craniopharyngioma usually had an intrasellar extension. Due to varied clinical manifestations, neuroimaging usually shows evidence of heterogeneous, mixed lesion with cystic and calcified component, which on contrast administration solid part showing uniform contrast enhancement. However, rarely it may also show involvement of orbit or intracranial extension into basifrontal region.
This lesion based on clinical symptomatology and CT scan and MRI findings infrasellar craniopharyngioma needs to be differentiated from. Depending on predominant content of lesion on neuroimaging is cystic component, mucocele should be differentiated, however if predominant solid components, carcinoma of paranasal sinus, chordoma, juvenile angiofibroma should be kept as possibility

Surgery is the main modality of initial treatment followed by radiotherapy if residual mass is present. Surgery aims for drainage of cyst with excision of capsule and total excision of solid component. Surgery is safe and usually do aggravate fresh neurological deficit. In our case transsphenoidal decompression of cyst with only partial removal of solid component was possible through transsphenoidal route, with adjuvant therapy was given for residual mass in follow-up period.

\section{Conclusion}

In the present case, tumour may initially arise from sellar region but extended either into sphenoid sinus and further extension into nasopharynx. These craniopharyngioma needs special precaution as it may present with nasal mass and ENT surgeon may accidentally attempt endoscopic biopsy.

\section{References}

1. Russell DS, Rubinstein IJ (1989) Pathology of tumours of the nervous system London, Edward Arnold, Eds.

2. Mott FW, Barrett Jowl (1899) Three cases of tumours of the third ventricles. Arch Neurol (Lon) 1: 417-440.

3. Erdheim J, Uber (1904) hypophysen angs ages wustle und Hirnschalesteatome. Akad Wiss (Wien) 113: 537-726.

4. Bock E (1924) Beitrazur Pathologie der Hypophyse. Virchows Arch Pathol Anat 252 98-112.

5. Cooper PR, Ransohoff J (1972) Craniopharyngioma originating in the sphenoid bone Case report. J Neurosurg 36: 102-106. [Crossref]

6. Drummond WAD (1938) Infrasellar admantinoma. Proc R Soc Med 31: 200-207.

7. Fujitani K, Hakuba A, Kojima S, Mishima Y, Tsujimoto T, et al. (1979) Craniopharyngioma, originating in the sphenoid sinus, extending into the nasal cavity. No Shinkei Geka 7: 181-186. [Crossref]

8. Hamburger CA, Hamme G, Norlem G, et al. (1960) Surgical removal of craniopharyngioma. Radical removal by the transsphenoidal approach. Acta Otolaryngol 52: 285-292.

9. Herrmann G (1923) Kasuistischer Beitrag zu den Hypophysentumoren. Med Klin 19 826-828.

10. Ishiyama R, Yasue M, Sanada S, Yuki K, Nakamura N (1977) Rare cases of craniopharyngioma, extending into the nasopharynx--two case reports. Neurol Med Chir (Tokyo) 17. [Crossref]

11. Illum P, Elbrond O, Nehen AM (1977) Surgical treatment of nasopharyngeal craniopharyngioma. Radical removal by transpalatal approach. J Laryngol Otol 91: 227-223. [Crossref]

12. Johnson NE (1962) Craniopharyngioma--review with a discussion of transpalatal approach. Laryngoscope 72: 1731-1749. [Crossref]

13. Maier HC (1985) Craniopharyngioma with erosion and drainage into the nasopharynx. An autobiographical case report. J Neurosurg 62: 132-134. [Crossref]

14. Majlessi H, Shariat AS, Katirai A (1978) Nasopharyngeal craniopharyngioma. Case report. J Neurosurg 49: 119-120. [Crossref]

15. Northfield DW (1957) Rathke-pouch tumours. Brain 80: 293-312. [Crossref]

16. Podoshin L, Rolan L, Altman MM, Peyser E (1970) 'Pharyngeal' craniopharyngioma. J Laryngol Otol 84: 93-99. [Crossref]

17. Prasad U, Kwi NK (1975) Nasopharyngeal craniopharyngioma. J Laryngol Otol 89: 445-452. [Crossref] 
18. Sato M (1944) A tumor originating from the remnant of the hypophyseal duct in the sella turcica. Tohoku Ishi 27: 692.

19. Trible WM (1970) Destructive lesions of the sphenoid. South Med J 63: 849-852. [Crossref]

20. Zetlin H (1935) Admnatinoma of the hypophyseal stalk and sphenoid sinus. $A M J$ Cancer 23: 729-740.

21. Akimura T, Kameda H, Abiko S, Aoki H, Kido T (1989) Infrasellar craniopharyngioma Neuroradiology 31: 180-183. [Crossref]

22. Benitez WI, Sartor KJ, Angtuaco EJ (1988) Craniopharyngioma presenting as a nasopharyngeal mass: CT and MR findings. J Comput Assist Tomogr 12: 1068-1072. [Crossref]

23. Bret P, Beziat JL (1993) Sphenoido-nasopharyngeal craniopharyngioma. A case with radical excision by Le Fort I-type maxillotomy. Neurochirurgie 39: 235-240. [Crossref]

24. Byrne MN, Sessions DG (1990) Nasopharyngeal craniopharyngioma: case report and literature review. Ann Otol Rhinol Laryngol 99: 663- 669. [Crossref]

25. Chakrabarty A, Mitchell P, Bridges LR (1998) Craniopharyngioma invading the nasa and paranasal spaces, and presenting as nasal obstruction. Br J Neurosurg 12: 361-363. [Crossref]

26. Cheddadi D, Triki S, Gallet S, Marquet M, Muller JP, et al. (1996) Neonatal rhinopharyngeal obstruction due to craniopharyngioma. Arch Pediatr 3: 348-351. [Crossref]

27. Chen CJ (2001) Suprasellar and infrasellar craniopharyngioma with a persistent craniopharyngeal canal: case report and review of the literature. Neuroradiology 43: 760-762. [Crossref]

28. Falavigna A, Kraemer JL (2001) Infrasellar craniopharyngioma: case report. Arq Neuropsiquiatr 59: 424-430. [Crossref]

29. Bernat Gili A, García García B (1991) Craniopharyngioma of the nasopharynx. Apropos of a case. Acta Otorrinolaringol Esp 42: 269-272. [Crossref]
30. Graziani N, Donnet A, Bugha TN, Dufour H, Figarella-Branger D, et al. (1994) Ectopic basisphenoidal craniopharyngioma: case report and review of the literature. Neurosurgery 34: 346-349. [Crossref]

31. Herzog J, Makek M, Fisch U (1989) Lesions of Rathke's duct: another indication for the infratemporal fossa approach. Otolaryngol Head Neck Surg 101: 302-308. [Crossref]

32. Hillman TH, Peyster RG, Hoover ED, Nair S, Finkelstein SD (1988) Infrasellar craniopharyngioma: CT and MR studies. J Comput Assist Tomogr 12: 702-704. [Crossref]

33. Jiang RS, Wu CY, Jan YJ, Hsu CY (1998) Primary ethmoid sinus craniopharyngioma: a case report. J Laryngol Otol 112: 403-405. [Crossref]

34. Kanungo N, Just N, Black M, Mohr G, Glikstein R, et al. (1995) Nasopharyngeal craniopharyngioma in an unusual location. AJNR Am J Neuroradiol 16: 1372-1374. [Crossref]

35. Lewin R, Ruffolo E, Saraceno C (1984) Craniopharyngioma arising in the pharyngeal hypophysis. South Med J 77: 1519-1523. [Crossref]

36. Maiuri F, Corriero G, Elefante R, Cirillo S, Giamundo A (1987) Craniopharyngioma of the cranial base and nasopharynx. Surg Neurol 27: 191-194. [Crossref]

37. Mukada K, Mori S, Matsumura S, Uozumi T, Goishi J (1984) Infrasellar craniopharyngioma. Surg Neurol 21: 565-571. [Crossref]

38. Mozota Ortiz JR, Medina Sola JJ, Aguado Martínez F, Alfaro García J, Hueto Prado J (1988) Craniopharyngioma of the cavum: report of a case. Acta Otorrinolaringol Esp 39: 119-121. [Crossref]

39. Pharaboz C, Merran S, Cordoliani Y, Rizzoli P (1989) Rhinopharyngeal craniopharyngioma. CT X-ray and MRI aspects. J Radiol 70: 573-575. [Crossref]

40. Pheline C, Jamois Y, Engel PH, et al. (1981) Craniopharyngiome ectopique basisphenoidal. Abord par voie base, nasoseptale, puis antro - ethmoidale. Neurochirurgie 27: 221-224.

Copyright: (C2017 Satyarthee GD. This is an open-access article distributed under the terms of the Creative Commons Attribution License, which permits unrestricted use, distribution, and reproduction in any medium, provided the original author and source are credited. 